\title{
Vitelline duct pathologies in neonates
}

\author{
Suleyman Celebi, ${ }^{1}$ Seyithan Ozaydin, ${ }^{1}$ Esra Polat, ${ }^{2}$ Cemile Basdas, ${ }^{1}$ Elmas Reyhan Alim, ${ }^{1}$ Serdar Sander ${ }^{1}$ \\ Department of Pediatric Surgery, Kanuni Sultan Suleyman Training and Research Hospital, Istanbul, Turkey \\ Department of Pediatric Gastroenterology, Kanuni Sultan Suleyman Training and Research Hospital, Istanbul, Turkey
}

\begin{abstract}
OBJECTIVE: The aim of this study was to review the management of pediatric cases of vitelline duct pathology (VDP) detected surgically or incidentally during the neonatal period and the outcomes.

METHODS: The data of newborns who were symptomatic and underwent VDP resection or who were incidentally diagnosed with VDP at a single institution between 1985 and 2015 were retrospectively analyzed in terms of age, sex, clinical features, treatment, perioperative findings, ectopic tissue pathology, and postoperative follow-up information.

RESULTS: Among the 36 newborns enrolled in this study, 26 were male and 10 were female (2.6:1). The median weight was $2400 \mathrm{~g}$ (range: 800-3090 g). In 16 cases (14 males and 2 females; 7:1) the VDP was surgically repaired. Pathological evaluation indicated that $43 \%(n=7)$ of the cases had ectopic gastric mucosa. VDP was incidentally discovered in 12 males and 8 females (1.5:1). VDP was removed in 10 cases (50\%) and left intact in others. Ectopic gastric mucosa was observed in $10 \%$ of the VDP removal cases. Ectopic gastric tissue was more prevalent in the surgical VDP cases than in the incidentally discovered and VDP removal cases $(p<0.05)$. Male predominance was greater in the surgically repaired cases than in the incidentally discovered cases $(p<0.05)$. One patient whose VDP was discovered incidentally was admitted 3 years later with obstruction due to intussusception caused by Meckel's diverticulum, and 1 patient was admitted with rectal bleeding at 11 years of age.
\end{abstract}

CONCLUSION: Symptomatic VDP in the newborn demonstrates a significant gender difference. Symptomatic cases are more likely to have ectopic gastric tissue than non-symptomatic cases. Incidentally detected cases without removal should be followed closely for future complications.

Keywords: Meckel's diverticulum; neonates; vitelline duct pathologies.

Cite this article as: Celebi S, Ozaydin S, Polat E, Basdas C, Alim ER, Sander S. Vitelline duct pathologies in neonates. North Clin Istanb 2018;5(3):211-215.

$\mathrm{T}$ he vitelline duct (VD) is an embryonic structure providing communication from the yolk sac to the midgut during fetal development [1]. Normally, it obliterates spontaneously and separates from the intestine between approximately the 5th and 9th weeks of gestation [2]. The obliterative process begins at the umbilical end of the duct and extends toward the intestine. Disruption of this process results with intestinal end or residents, causing vitelline duct pathology (VDP)[3]. VDP could occur in a variety of abnormalities, such as Meckel's diverticulum, vitelline cyst, persistent fibrous cord, or umbilical sinus; Alternatively, VD may be patent and present as an omphaloileal fistula and after birth, the infant presents with umbilical discharge resembling small bowel content [4].

VD remnants are said to be present in $2 \%-4 \%$ of all routine postmortem examinations $[5,6]$. The complications are common in infants and male children, which can be serious $[7,8]$ but most reports focus on VD on symptomatic Meckel's diverticulum, whereas other anomalies are given little attention. Our newborn series is one of the largest series in the literature.

Received: April 28, 2017 Accepted: October 04, 2017 Online: April 21, 2018

Correspondence: Dr. Suleyman CELEBI. Kanuni Sultan Suleyman Egitim ve Arastirma Hastanesi, Cocuk Cerrahisi Anabilim Dali, Istanbul, Turkey.

Phone: +90 5057456577 e-mail: celebisuleyman@hotmail.com

(c) Copyright 2018 by Istanbul Provincial Directorate of Health - Available online at www.northclinist.com 
TABLE 1. Clinical characteristics of surgically repaired VDP

\begin{tabular}{lccccccc} 
Surgical Cases & $\begin{array}{c}\text { All patients } \\
(\mathrm{n}=16)\end{array}$ & $\begin{array}{c}\text { Age } \\
\text { (postnatal } \\
\text { day })\end{array}$ & $\begin{array}{c}\text { Gender } \\
(\text { male: } \\
\text { female) }\end{array}$ & $\begin{array}{c}\text { Simple } \\
\text { diverticulectomy } \\
(n=2)\end{array}$ & $\begin{array}{c}\text { Wedge-shaped } \\
\text { excision }(n=3)\end{array}$ & $\begin{array}{c}\text { Segmental bowel } \\
\text { resection }(n=11)\end{array}$ & $\begin{array}{c}\text { Ectopic Gastric } \\
\text { tissue }(n)\end{array}$ \\
\hline Patent Vitelline duct & 11 & $4-17$ & $10: 1$ & 2 & 2 & 7 & 5 \\
Volvulus & 2 & 2.5 & $1: 1$ & 0 & 0 & 2 & 0 \\
Ileal dysgenesis & 1 & 4 & $1: 0$ & 0 & 0 & 1 & 1 \\
Littre hernia & 1 & 7 & $1: 0$ & 0 & 1 & 0 & 1 \\
MD perforation & 1 & 3 & $1: 0$ & 0 & 0 & 1 & 1
\end{tabular}

Surgical repaired cases has statistically significant male predominance $(p<0.05)$

The objective of this study was to review the management and outcomes of surgically and incidentally diagnosed VDP in the neonatal period, using contemporary data from an institutional database.

\section{MATERIALS AND METHODS}

Newborn patients who underwent surgery due to VDP or who were incidentally diagnosed at a single institution from 1985 to 2015 were retrospectively analyzed. After approval of the study by the Institutional Review Board of Medical Ethics Committee, informed consent was obtained from the children's parents. Patient-related information included gender, the postnatal day at presentation and surgery, clinical features, laboratory data, and perioperative findings, including operative procedures, pathology, and postoperative follow-up.

Based on the diagnoses at presentation, the enrolled patients were divided into two groups. Group 1 consisted of surgical cases due to VDP that was resected in all cases. Group 2 consisted of incidentally discovered cases of patients who had undergone surgery for other newborn pathologies. In Group 1, VDP was classified as the presence of patent VD, a cyst, and a fistula, as diagnosed by a physician. In Group 2, VDP was classified as having been discovered incidentally during surgery for other congenital gastrointestinal malformations.

The clinical manifestations were also included if there was intestinal hemorrhage, inflammation, and intestinal obstruction. Intestinal obstruction was defined when VD was presented with bilious vomiting and when intussusception, adhesion ileus, hernia, torsion, or other mechanical intestinal obstructions were found during surgery.

Statistical analysis was performed using SPSS soft- ware (version 17.0; SPSS Inc., Chicago, IL, USA). Continuous variables were presented as means and standard deviations. Qualitative variables were presented as total numbers and percentages. The continuous variables were compared using the Mann-Whitney U-test for nonparametric variables. The statistical significance level was set at $\mathrm{p}<0.05$.

\section{RESULTS}

Among the 36 newborns enrolled, 26 were male and 10 were female. There were 16 patients ( 14 boys, two girls) who had surgery for VDP so the male-to-female ratio was $7: 1$. Median weight was 2,400 g (range: 800-3090 g). Median age was 6 days ( $0-17$ days). Eleven newborns had a patent vitelline duct (PVD). The main complaint was watery and mucous discharge from the umbilicus. One patient with PVD had an associated anomaly (intestinal malrotation). Other surgical cases were two patients with volvulus, one with ileal dysgenesis and segmental mega-ileum within MD, and one with inguinal hernia in which MD was inside the hernia sac and was strangulated, being discovered during surgery (Table 1). One patient was operated on because of MD perforation (Fig. 1). Two of the 16 patients who were operated on because of VDP had multiple organ failure and died of cardiopulmonary arrest; the other 14 (87\%) patients were discharged without additional complications. Ectopic gastric mucosa was detected in histopathological evaluations in seven (43\%) histopathological cases.

Twenty cases were found incidentally, 12 males and eight females. The male-to-female ratio of asymptomatic cases was $1.5: 1$. The sex discrepancy was higher in the surgically repaired category than in the incidental 

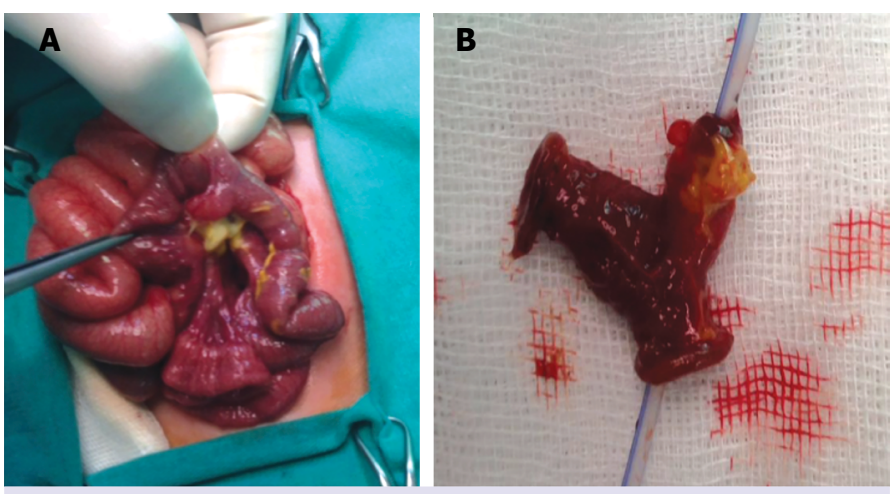

FigURE 1. (A) Perforation due to Meckel Diverticulitis in newborn patient. Patient was born as a result of in vitro fertilization twin pregnancies at 36 weeks gestational age. Twins are one male and one female. Male patient was operated on because of MD (B) MD underwent segmental bowel resection.

TABLE2. Clinical characteristics of Incidentally discovered cases of VDP

Total Patient ( $\mathrm{n}$ )

Male: Female

Abdominal Wall Defect (AWD)

$12(60 \%)$

AWD with Intestinal perforation

$3(15 \%)$

Gastrointestinal anomaly

Ileal atresia

2

Duodenal atresia

2

Pouch colon

Malrotation

Anal atresia

Congenital Diaphragmatic Hernia

Surgery $(\mathrm{n})$

Ectopic Gastric Tissue

Ectopic Tissue Surgical repaired-

Incidental Discovered

$10(50 \%)$

$1(10 \%)$

$4: 1$ mucosa was present in $10 \%$ cases. Ectopic tissues were more prevalent in symptomatic VDP cases than incidental discovered and VDP removal cases (43\%: 10\%, $\mathrm{p}<0.05)$.

One patient who was discovered incidentally and leaved intact during follow-up was admitted with obstruction due to Meckel's diverticulum when he was 3 years old and underwent surgery for an intussusception. The other one presented with an intestinal hemorrhage when the patient was 11 years old, and diverticulitis was discovered during the surgery.

There were 13 (50\%) patients who underwent segmental bowel resection of an ileal segment, nine (34\%) who underwent wedge-shaped resection, and four (15\%) who underwent simple diverticulectomy

In the neonatal period, the following pathological findings were reported: predominantly mucosal congestion with VDP, edema, hemorrhage, or ischemic changes. In histopathological examinations for ectopic tissue, 11 cases had gastric mucosa. With regard to the pathology, six cases did not have clearly defined findings and intense inflammation of the diverticulum mucosa due to necrosis was reported. All cases of MD containing gastric mucosa were symptomatic, and one patient who was diagnosed incidentally, during follow-up was operated on because of bleeding when he was 11 years old. This patient also had ectopic gastric mucosa in the pathological examination.

\section{DISCUSSION}

The VD is the embryonic communication between the yolk sac and the midgut, but it normally closes and disappears during the development process $[9,10]$. A persistent intestinal end or residents can cause VDPs. Clinical presentations in decreasing order of likelihood include intestinal obstruction, gastrointestinal bleeding, acute intraabdominal inflammation, and umbilical anomalies that have junction with the ileum $[11,12]$.

Symptomatic presentation of VDP in neonates is rare [13]. Thus, our study focused on VDP discovered in newborns. In this study, the most common pathology in newborns was patent VD and secondly incidentally discovered cases during omphalocele, gastroschisis and umbilical cord prolapse repairs and one patient who had a Littre hernia was admitted with strangulated hernia. Segmental ileum dilatation (SID), an anomaly also known as ileal dysgenesis, was found in one patient. ing surgery for diaphragmatic hernia. VDP in the other discovered cases was left intact (Table 2). Ectopic gastric 
There were eight cases of SID associated with VD reported till now; only three were in neonates [14]. Neonatal VDP can also present as ileal volvulus with resultant infarction of the diverticulum [15] and the ileum, similar to the pathology in two of our cases. Looking at the other presentations, we found 12 cases of neonatal Meckel's diverticulum with perforation that have been described in the literature [16]. The causes of perforation include spontaneous inflammatory ulceration with heterotopic mucosa, congenital muscle defect, or perforation secondary to Hirschsprung's disease. Our case series has one such case.

We had incidentally discovered VDs during repair of the newborn congenital anomalies, and some were left intact according to surgeon preference. Two of these cases were readmitted during follow-up-one of them was admitted with intussusception at the age of 3 years and the other with bleeding 11 years later.

Ectopic tissue could be detected in VDP [3]. Numerous explanations have been put forward to account for the presence of aberrant elements. The most acceptable is the endothelial lining of the embryo forms cell groups which function as a primitive digestive system and that, while normally this system regresses as soon as its function ceases, occasionally "a vestige of heterotopic tissue remains as a consequence of retarded retrogression of the vitellointestinal duct [17]. Ectopic tissue detection rate in VDs is higher in children than in adults [3]. It is known that if the ectopic tissue contains gastric mucosa, it has a greater chance to become symptomatic than those without gastric mucosa MD [18]. Heterotopic gastric mucosa (HGM) can be symptomatic more frequently in younger and male patients (e.g., bleeding), usually derived from an adjacent ileal mucosal ulceration, intestinal obstruction, and diverticulitis [19]. There is convincing evidence for MD removal in young patients with suspicion of ectopic mucosa. Rutherford and Aker observed ectopic gastric mucosa in all symptomatic patients. [20] Only a $6 \%$ incidence of heterotopic tissue was found in autopsy specimens of asymptomatic diverticulum. In one study among 30 gastric-mucosa-containing MD, 25 (83\%) were found in the pediatric group and five (17\%) were found in the adult group [21]. In our study, nearly half of the surgically repaired group had ectopic tissue; the inflammation in the rest may have prevented the pathological confirmation of ectopic gastric mucosa.

One of the infants in our study who weighed 2,300 $\mathrm{g}$ had an early postnatal volvulus. Volvulus occurs when the small bowel twists around a fibrous cord, or Meckel's band, tethering MD to the umbilicus. In addition, MD could be complicated with intestinal obstruction secondary to internal hernia, as observed in one of our cases.

Male patients were more likely to have HGM than female patients; hence, symptomatic VDP patients were more likely to be male [3]. Even with no difference in the prevalence of asymptomatic MD between males and females, symptomatic MD has a male predominance, with a male-to-female ratio ranging from $2: 1$ to $5: 1$ in children [22, 23]. In our study including only newborns, we found major male dominance, with a ratio of almost $7: 1$. Case reports in the literature on neonatal MD almost all males [15]. One of the largest series from the Mayo Clinic reported that the diverticulum containing ectopic or abnormal tissue is associated with symptomatic diverticulum in male patients, and they suggests resection in such cases [3]. In our one patient. This patient was born as a result of in vitro fertilization twin pregnancies at 36 weeks gestational age. Twins are one male and one female. Male patient was operated on because of MD perforation. But female has no MD symptoms.

Bleeding in ectopic gastric mucosa was secondary to the ileal mucosal breakdown as a result of acid-producing parietal cells within MD [3]. The theory is based on the inheritance of an acid-secreting ability, possibly a parietal cell mass at the top of the normal range and the consequence of hyperacidity [20]. Those reported cases of ulcers involving gastric mucosa are of doubtful validity, and Gezer [24] suggested that the actual ulceration occurs in an island of ileal mucosa within the gastric rest. According to Gezer, the neck of the diverticulum is the most common site for the ulcer, followed by the body, the tip, and lastly the immediately neighboring ileum. One of our incidentally discovered cases was admitted because of bleeding 11 years later during follow-up; the pathology in case was ectopic gastric tissue.

Omphalomesenteric duct anomalies occur in approximately $2 \%$ of newborns. In $6 \%$ of these infancts, the duct remains patent. In a study of approximately 1,000 umbilical cords and placentas, microscopic analysis revealed embryonic remnants of $23.1 \%$ samples. Furthermore, up to $6.6 \%$ of these omphalomesenteric were VD remants [24].

When connected to the ileum, a PVD may have a wide lumen or be a high-output fistula. This may lead to fluid and electrolyte loss, especially in neonates, and treatment should be expeditious. Early surgical manage- 
ment is important as it may cause severe complications, which may result in mortality in up to $18 \%$ cases, especially in the newborn period [25].

In our series it is striking to see high rates of gastroschisis and omphalocele in VDPs.

The most recent hypothesis was sectional by Stevenson et al. [26], who suggested that the defect in the gastroschisis is caused by the failure of the yolk sac and related vitelline structures to be incorporated into the umbilical stalk. In addition to the umbilicus, the abdominal wall has a second opening through which the midpoint of the gut (Meckel's point) is attached to the exteriorized vitelline structures. Gastroschisis and omphaloceles that we see with VDP supports the Stevenson's hypothesis that midline with such pathology.

\section{CONCLUSION}

The VD complications to which they are subject are serious and are commonest in newborns. Presenting symptoms were related to age, ectopic tissue, and showing gender differences. Male predominance in newborns is higher than children and adults.

Conflict of Interest: No conflict of interest was declared by the authors.

Financial Disclosure: The authors declared that this study has received no financial support.

Authorship Contributions: Concept - S.C., S.O.; Design - S.C., E.S., C.B., S.S.; Supervision - S.C., E.A., C.B., S.S.; Materials - S.C., E.A., E.R.A., S.S.; Data collection \&/or processing - S.C., S.O., E.P., E.S., S.S.; Analysis and/or interpretation - S.C., C.B., E.P., E.R.A., S.S.; Writing - S.C., E.P.; Critical review - S.C., E.P., S.S.

\section{REFERENCES}

1. Yahchouchy EK, Marano AF, Etienne JC, Fingerhut AL. Meckel's diverticulum. J Am Coll Surg 2001;192:658-62. [CrossRef]

2. Sagar J, Kumar V, Shah DK. Meckel's diverticulum: a systematic review. J R Soc Med 2006;99:501-5. [CrossRef]

3. Park JJ, Wolff BG, Tollefson MK, Walsh EE, Larson DR. Meckel diverticulum: the Mayo Clinic experience with 1476 patients (1950-2002). Ann Surg 2005;241:529-33. [CrossRef]

4. Kadian YS, Verma A, Rattan KN, Kajal P. Vitellointestinal Duct Anomalies in Infancy. J Neonatal Surg 2016;5:30. [CrossRef]

5. Menezes M, Tareen F, Saeed A, Khan N, Puri P. Symptomatic Meckel's diverticulum in children: a 16-year review. Pediatr Surg Int 2008;24:575-7. [CrossRef]
6. Stone PA, Hofeldt MJ, Campbell JE, Vedula G, DeLuca JA, Flaherty SK. Meckel diverticulum: ten-year experience in adults. South Med J 2004;97:1038-41. [CrossRef]

7. Tseng YY, Yang YJ. Clinical and diagnostic relevance of Meckel's diverticulum in children. Eur J Pediatr 2009;168:1519-23. [CrossRef]

8. St-Vil D, Brandt ML, Panic S, Bensoussan AL, Blanchard $\mathrm{H}$. Meckel's diverticulum in children: a 20-year review. J Pediatr Surg 1991;26:1289-92. [CrossRef]

9. Cserni G. Gastric pathology in Meckel's diverticulum. Review of cases resected between 1965 and 1995. Am J Clin Pathol 1996;106:782-5.

10. Gandy J, Byrne P, Lees G. Neonatal Meckel's diverticular inflammation with perforation. J Pediatr Surg 1997;32:750-1. [CrossRef]

11. Elsayes KM, Menias CO, Harvin HJ, Francis IR. Imaging manifestations of Meckel's diverticulum. AJR Am J Roentgenol 2007;189:81-8.

12. Baker Al Jr, Marshall SF. Meckel's diverticulum: a report of ninety-three cases. Am Surg 1955;21:1173-81.

13. Ko SF, Tiao MM, Huang FC, Hsieh CS, Huang CC, $\mathrm{Ng} \mathrm{SH}$, et al. Internal hernia associated with Meckel's diverticulum in 2 pediatric $\mathrm{pa}$ tients. Am J Emerg Med 2008;26:86-90. [CrossRef]

14. Ojha S, Menon P, Rao KL. Meckel's diverticulum with segmental dilatation of the ileum: radiographic diagnosis in a neonate. Pediatr $\mathrm{Ra}$ diol 2004;34:649-51. [CrossRef]

15. Sy ED, Shan YS, Tsai HM, Lin CH. Meckel's diverticulum associated with ileal volvulus in a neonate. Pediatr Surg Int 2002;18:529-31.

16. Chang YT, Lin JY, Huang YS. Spontaneous perforation of Meckel's diverticulum without peritonitis in a newborn: report of a case. Surg Today 2006;36:1114-7. [CrossRef]

17. Cullen JJ, Kelly KA, Moir CR, Hodge DO, Zinsmeister AR, Melton LJ 3rd. Surgical management of Meckel's diverticulum. An epidemiologic, population-based study. Ann Surg 1994;220:564-8. [CrossRef]

18. Matsagas MI, Fatouros M, Koulouras B, Giannoukas AD. Incidence, complications, and management of Meckel's diverticulum. Arch Surg 1995;130:143-6. [CrossRef]

19. Çelebi S. Male predominance in Meckel's diverticulum: A hyperacidity hypotheses. Med Hypotheses 2017;104:54-7. [CrossRef]

20. Rutherford RB, Akers DR. Meckel's diverticulum: a review of 148 pediatric patients, with special reference to the pattern of bleeding and to mesodiverticular vascular bands. Surgery 1966;59:618-26.

21. Dumper J, Mackenzie S, Mitchell P, Sutherland F, Quan ML, Mew D. Complications of Meckel's diverticula in adults. Can J Surg 2006; 49:353-7.

22. Ymaguchi M, Takeuchi S, Awazu S. Meckel's diverticulum. Investigation of 600 patients in Japanese literature. Am J Surg 1978;136:247-9.

23. Levy AD, Hobbs CM. From the archives of the AFIP. Meckel diverticulum: radiologic features with pathologic Correlation. Radiographics 2004;24:565-87. [CrossRef]

24. Gezer HÖ, Temiz A, İnce E, Ezer SS, Hasbay B, Hiçsönmez A. Meckel diverticulum in children: Evaluation of macroscopic appearance for guidance in subsequent surgery. J Pediatr Surg 2016;51:1177-80.

25. Rao PL, Mitra SK, Pathak IC. Patent vitello-intestinal duct. Indian J Pediatr 1979;46:215-8. [CrossRef]

26. Stevenson RE, Rogers RC, Chandler JC, Gauderer MW, Hunter AG. Escape of the yolk sac: a hypothesis to explain the embryogenesis of gastroschisis. Clin Genet 2009;75:326-33. [CrossRef] 